\begin{tabular}{|c|c|c|c|}
\hline \multirow{2}{*}{$\begin{array}{r}\text { Case Reports in } \\
\text { Gastroenterology }\end{array}$} & \multicolumn{2}{|c|}{ Case Rep Gastroenterol 2016;10:518-524 } & \multirow[b]{2}{*}{$\begin{array}{l}\text { Karger } \\
\text { Open access }\end{array}$} \\
\hline & $\begin{array}{l}\text { DOI: 10.1159/000445184 } \\
\text { Publisnea onithe: Uctover 6, } 2016\end{array}$ & $\begin{array}{l}\text { (c) } 2016 \text { The Author(s) } \\
\text { Published by S. Karger AG, Basel } \\
\text { www.karger.com/crg }\end{array}$ & \\
\hline & $\begin{array}{l}\text { This article is licensed under th } \\
\text { International License (CC BY-NC) } \\
\text { Usage and distribution for comme }\end{array}$ & $\begin{array}{l}\text { mons Attribution-NonCommercial } 4 . \\
\text { ger.com/Services/OpenAccessLicense } \\
\text { quires written permission. }\end{array}$ & \\
\hline
\end{tabular}

\title{
A Rare Case of Gastric Variceal Hemorrhage Secondary to Infiltrative B-Cell Lymphoma
}

\author{
Adrienne Lenhart $^{\mathrm{a}} \quad$ Juan Fernandez-Castillo ${ }^{a} \quad$ Keith Mullins $^{b}$ \\ Reena Salgiab \\ ${ }^{a}$ Department of Internal Medicine, Henry Ford Hospital, Detroit, Mich., USA; ${ }^{b}$ Division of \\ Gastroenterology and Hepatology, Henry Ford Hospital, Detroit, Mich., USA
}

\section{Keywords}

Gastric variceal hemorrhage $\cdot$ B-cell lymphoma $\cdot$ Portal hypertension

\begin{abstract}
Portal hypertension commonly arises in the setting of advanced liver cirrhosis and is the consequence of increased resistance within the portal vasculature. Less commonly, left-sided noncirrhotic portal hypertension can develop in a patient secondary to isolated obstruction of the splenic vein. We present a rare case of left-sided portal hypertension and isolated gastric varices in a patient with large B-cell lymphoma, who was treated with splenic artery embolization. The patient is a 73-year-old male with no previous history of liver disease, who presented with coffee ground emesis and melena. On admission to hospital, he was found to have a hemoglobin level of $3.4 \mathrm{~g} / \mathrm{l}$. Emergent esophagogastroduodenoscopy showed isolated bleeding gastric varices (IGV1 by Sarin classification) in the fundus and cardia with subsequent argon plasma coagulation injection. He was transferred to our tertiary center where work-up revealed normal liver function tests, and abdominal ultrasound showed patent hepatic/portal vasculature without cirrhosis. MRI demonstrated a large heterogeneously enhancing mass in the pancreatic tail, with invasion into the spleen and associated splenic vein thrombosis. Surgery consultation was obtained, but urgent splenectomy was not recommended. The patient instead underwent splenic artery embolization to prevent future bleeding from his known gastric varices. Pathology from a CT-guided biopsy was consistent with diffuse large B-cell lymphoma. PET imaging showed uptake in the splenic hilum/pancreatic
\end{abstract}




\section{Case Reports in Gastroenterology}

Case Rep Gastroenterol 2016;10:518-524 DOI: $10.1159 / 000445184$ (c) 2016 The Author(s). Published by S. Karger AG, Basel www.karger.com/crg

Lenhart et al.: A Rare Case of Gastric Variceal Hemorrhage Secondary to Infiltrative B-Cell Lymphoma

tail region with no additional metastatic involvement. He was evaluated by the Hematology Department to initiate R-CHOP chemotherapy. During his outpatient follow-up, he reported no further episodes of melena or hematemesis. To the best of our knowledge, there have only been two published case reports of large B-cell lymphoma causing upper gastrointestinal bleeding from isolated gastric varices. These cases were treated with splenectomy or chemotherapy alone. Thus far, splenectomy has been the standard treatment approach for splenic vein thrombosis with clinical complication, such as gastric variceal bleeding. We present a case of successful treatment of bleeding isolated gastric varices using a less invasive and less morbid approach through splenic artery embolization. This case highlights the need for an increased awareness of the diverse etiologies of left-sided portal hypertension and isolated gastric varices, as well as the consideration of minimally invasive management strategies.

\section{Introduction}

Portal hypertension commonly arises in the setting of advanced cirrhosis and is the direct consequence of increased resistance within the portal vasculature. This process can be complicated by the development of ascites and gastroesophageal varices, among other complications. Less commonly, portal hypertension can arise in a noncirrhotic patient secondary to obstruction of the splenic vein [1]. This phenomenon, known as left-sided portal hypertension (LSPH), is a rare clinical syndrome, which may result in the formation of isolated gastric varices (IGV). After the splenic vein becomes occluded, blood drains through the short gastric veins at increased pressures, resulting in dilation of submucosal structures and the formation of IGV [1]. These varices have the potential to rupture and subsequently result in significant gastrointestinal (GI) hemorrhage.

Although it comprises less than $5 \%$ of all cases of portal hypertension, the incidence of LSPH has been increasing over the past several decades, likely secondary to an increased awareness of its existence $[1,2]$. Consequently, IGV due to LSPH should be considered in the differential diagnosis of patients presenting with upper GI bleeding, despite having normal liver function. The splenic vein obstruction or thrombosis that results in LSPH is usually seen in association with pancreatic disorders, secondary to the close anatomic relationship between the splenic vasculature and the pancreas [1]. Nonpancreatic etiologies of LSPH have been reported in the literature, but are much less common [1-3]. Splenectomy is currently the gold standard of treatment for bleeding IGV; however, less invasive alternatives, such as transcatheter splenic artery embolization are currently being explored. We present a rare case of LSPH and IGV in a patient with large B-cell lymphoma, who was ultimately treated with splenic artery embolization.

\section{Case}

The patient is a 73-year-old male with a past medical history of hyperlipidemia, hypertension, and obstructive sleep apnea who originally presented to hospital with a 3-day history of coffee ground emesis and melena. He also reported associated symptoms of dizziness, weakness, palpitations, and fatigue. In the Emergency Department, he was initially found to be hypotensive and tachycardic, with a hemoglobin level of $3.4 \mathrm{~g} / \mathrm{dl}$ and an international normalized ratio of 1.29. He was aggressively resuscitated and transfused multiple units of 
Lenhart et al:: A Rare Case of Gastric Variceal Hemorrhage Secondary to Infiltrative B-Cell Lymphoma

packed red blood cells with appropriate response. Emergent esophagogastroduodenoscopy (EGD) was performed showing isolated bleeding varices (IGV) in the gastric fundus and was subsequently treated with argon plasma coagulation. The patient was then started on intravenous protonix and octreotide drips and transferred to our tertiary care center for evaluation of suspected underlying cirrhosis and for possible transjugular intrahepatic portosystemic shunt procedure.

The patient denied any previous history of liver disease, injection drug use, or current alcohol use. However, he did admit to having one previous episode of hematemesis over 40 years ago, which required blood transfusion. Upon further questioning, he also reported significant weight loss, with his weight decreasing from 318 to 280 pounds over a 6 -month period. He underwent repeat EGD at our hospital, which again demonstrated multiple clusters of medium-sized IGV (IGV1 by Sarin Classification) (fig. 1). Further work-up revealed normal liver function tests, and HIV/hepatitis screening was negative. Abdominal ultrasound showed patent hepatic and portal vasculature with no ultrasonographic evidence of cirrhosis. MRI and CT imaging demonstrated a large heterogeneously enhancing mass in the pancreatic tail with direct invasion into the spleen. There was also evidence of splenic vein thrombosis and enlarged abdominal lymph nodes. No metastatic disease was visualized in the liver or thorax (fig. 2; the arrow is pointing to the perisplenic mass). Because of his combined clinical history and abnormal findings on imaging, there was initial concern for pancreatic malignancy, and he subsequently underwent CT-guided biopsy of the perisplenic mass. Surgery consultation was obtained to address possible resection of the mass to control the variceal bleed. However, given the patient's high likelihood of significant morbidity with surgical intervention, urgent splenectomy was not recommended. Rather, the patient underwent IR-guided splenic artery embolization to prevent future bleeding from his known gastric varices. He was discharged in stable condition with outpatient follow-up.

Pathology of the perisplenic mass was consistent with stage IVA-E diffuse large B-cell lymphoma (fig. 3; pathology slide with hematoxylin and eosin staining). Immunohistochemical staining was positive for CD20, CD45, CD10, BCL6, and BCL2, and negative for CK19, CD3, CD5, cyclin D1, TTF-1, and TdT. MIB1 staining showed a proliferation rate of follicular structures up to $30 \%$. PET-CT revealed intense fluorodeoxyglucose uptake within the known abdominal mass, with no additional metastatic involvement. The patient was evaluated by the Hematology Department to initiate R-CHOP chemotherapy. He reported no further episodes of melena or hematemesis during his follow-up appointments.

\section{Discussion}

As stated previously, LSPH is an uncommon clinical condition, which may result in the formation of IGV. LSPH typically results from obstruction of the splenic vein, which can occur with thrombosis or mass effect from adjacent structures. Many cases of IGV are discovered incidentally; however, rupture of these varices can also present as GI bleeding in the form of melena or hematemesis. The incidence of upper GI bleeding in patients with LSPH ranges from 45 to $72 \%$ in reported studies [1-3]. Our particular patient presented with gastric variceal bleeding in the form of coffee ground emesis and melena.

Pancreatic disorders account for the majority of cases of LSPH, secondary to the location of the splenic vein posterior to the pancreas. Acute and chronic pancreatitis, followed by pancreatic malignancies (adenocarcinomas, islet cell carcinomas, and cystadenomas), are among the most commonly reported causes of LSPH and IGV. Other pancreatic etiologies, 


\section{Case Reports in Gastroenterology}

Case Rep Gastroenterol 2016;10:518-524

DOI: 10.1159/000445184

c 2016 The Author(s). Published by S. Karger AG, Basel www.karger.com/crg

Lenhart et al.: A Rare Case of Gastric Variceal Hemorrhage Secondary to Infiltrative B-Cell Lymphoma

such as pseudocysts, abscesses, and pancreas divisum, have also been reported in the literature [1-3]. Nonpancreatic etiologies of LSPH are less common but include metastatic malignancies (small cell lung cancer, renal cancer, gastric cancer, and colonic adenocarcinoma), lymphoma, surgical manipulations, retroperitoneal fibrosis, hypercoagulability disorders, and splenic artery aneurysms [1]. A diagnosis of LSPH is based on clinical history, radiographic imaging, and findings on upper endoscopy. Although somewhat invasive, angiography can also show filling deficits in the splenic vasculature and be used to confirm splenic vein thrombosis [1]. Endoscopic ultrasound has been shown to be superior to abdominal ultrasound for assessing the patency of the portal vasculature and should be considered when other diagnostic methods have failed to confirm the cause of bleeding gastric varices $[1,4]$. Contrast-enhanced CT venography and MR angiography with gadopentetate dimeglumine have also occasionally been used to aid in diagnosis [5, 6].

Mortality from gastric variceal bleeds has been reported to be as high as $52 \%$ at 1 year, due to the limited efficacy of endoscopic therapy and the high rate of recurrent bleeding $[1$, 7]. Various options have been used to treat the bleeding from gastric varices, including endoscopic injection sclerotherapy, band ligation, and balloon-occluded retrograde transvenous obliteration, as well as injection of cyanoacrylate glue [1]. There are, however, more definitive treatment options for symptomatic patients with LSPH outside of endoscopic therapy.

Splenectomy is currently the gold standard of treatment for IGV secondary to LSPH from either pancreatic or nonpancreatic processes. Surgical removal of the spleen decreases venous outflow through collateral circulations and decompresses IGV to prevent future bleeding [8]. To the best of our knowledge, there have only been two other published case reports of large B-cell lymphoma causing upper GI bleeding from IGV $[9,10]$. These cases were treated with splenectomy or chemotherapy alone. However, surgical splenectomy poses certain operative risks, especially in patients with multiple preexisting comorbidities. These risks include infection with encapsulated organisms, intra- and postoperative hemorrhage, thrombocytosis, pancreatitis, and gastric fistula formation, with reported morbidities and mortalities ranging from 8 to $52 \%$ and from 0 to $9 \%$, respectively [11,12]. One previous case report suggested that surgery might have been avoided in at least one case if the diagnosis of lymphoma had been considered preoperatively [9]. This illustrates the importance of recognizing the etiology of LSPH and considering less invasive management strategies when possible.

Transcatheter splenic artery embolization represents one of the less invasive alternatives to splenectomy as a treatment option for IGV, and it has been used with various degrees of success $[1,13]$. During this procedure, a catheter is passed through the splenic artery near the splenic hilum, and coils are deployed to occlude arterial blood supply to the spleen. This subsequently decreases venous return, lowers portal pressure within the variceal collateral vessels, and ultimately prevents future bleeding from IGV. Splenic artery embolization has been shown to be as effective as splenectomy in lowering portal pressure and avoids potential complications of postsplenectomy sepsis or unregulated thrombocytosis. Studies have reported that the overall complication rate of splenic artery embolization is around $33-52 \%[14,15]$. However, most of these complications are minor and include symptoms of fever, leukocytosis, abdominal pain, and hydrothorax. More severe complications are rare, including splenic abscesses and splenic infarction [14, 15]. Our patient was able to undergo successful treatment with splenic artery embolization, thus avoiding the potential risks of surgery, and had cessation of his variceal bleeding. 
Lenhart et al.: A Rare Case of Gastric Variceal Hemorrhage Secondary to Infiltrative B-Cell Lymphoma

Proximal portal decompressive procedures, such as transjugular intrahepatic portosystemic shunt, which are standard therapies in appropriate patients with liver cirrhosis and high portal pressures, do not have a role in the treatment of patients with isolated LSPH who typically are not cirrhotic and have normal portal pressures [1]. Recognizing this distinction emphasizes the importance of careful clinical evaluation for the cause of upper GI bleeding. Accurate diagnosis can help determine the safest and most effective approach to individualized therapy, thereby improving clinical outcomes.

\section{Conclusion}

We present a case of successful treatment of bleeding IGV using a less invasive and less morbid approach through splenic artery embolization. This case highlights the need for an increased awareness of the diverse etiologies of LSPH and IGV, and the importance of accurate diagnosis of the cause of bleeding in these patients. In many cases, a nonsurgical approach can offer equally effective treatment with less morbidity.

\section{Statement of Ethics}

The authors have no ethical conflicts to declare.

\section{Disclosure Statement}

The authors have no conflicts of interest to disclose.

\section{References}

Koklu S, Coban S, Yuksel O, Arhan M: Left-sided portal hypertension. Dig Dis Sci 2007;52:1141-1149. Madsen MS, Petersen TH, Sommer H: Segmental portal hypertension. Ann Surg 1986;204:72-77. Moossa AR, Gadd MA: Isolated splenic vein thrombosis. World J Surg 1986;9:384-390.

Lewis JD, Faigel DO, Morris JB, et al: Splenic vein thrombosis secondary to focal pancreatitis diagnosed by endoscopic sonography. J Clin Gastroenterol 1998;26:54-56.

-5 Vogelzang RL, Gore RM, Anschuetz SL, et al: Thrombosis of the splanchnic veins: CT diagnosis. AJR Am J Roentgenol 1988;150:93-96.

-6 Edelman RR, Zhao B, Liu C, et al: MR angiography and dynamic flow evaluation of the portal venous sytem. AJR Am J Roentgenol 1989;153:755-760.

-7 Kim T, Shijo H, Kokawa H, Tokumitsu H, Kubara K, Ota K, Akiyoshi N, Iida T, Yokoyama M, Okumura M: Risk factors for hemorrhage from gastric fundal varices. Hepatology 1997;25:307-312.

8 Bernades P, Baetz A, Levy P, et al: Splenic and portal venous obstruction in chronic pancreatitis. A prospective longitudinal study of a medical-surgical series of 266 patients. Dig Dis Sci 1992;37:340346.

9 Parekh R, Walia S, Zalawadia A, Siddiqui Y: A rare case of splenic lymphoma in a patient with polymyositis manifesting as gastric variceal bleeding. J Clin Gastroenterol 2015;8:92-96.

10 Chen BC, Wang HH, Lin YC, et al: Isolated gastric-variceal bleeding caused by splenic lymphomaassociated splenic vein occlusion. World J Gastroenterol 2013;19:6939-6940.

11 Patel NY, Chilsen AM, Mathiason MA, et al: Outcome and complications after splenectomy for hematologic disorders. Am J Surg 2012;204:1014.

12 Rosen M, Brody F, Walsh RM, et al: Outcome of laparoscopic splenectomy based on hematologic indication. Surg Endosc 2002;16:272. 


\section{Case Reports in \\ Gastroenterology}

\begin{tabular}{l|l}
\hline Case Rep Gastroenterol 2016;10:518-524 \\
\hline DOI: 10.1159/000445184 & $\begin{array}{l}\text { ○ 2016 The Author(s). Published by S. Karger AG, Basel } \\
\text { www.karger.com/crg }\end{array}$ \\
\hline
\end{tabular}

Lenhart et al:: A Rare Case of Gastric Variceal Hemorrhage Secondary to Infiltrative B-Cell Lymphoma

13 Li ZY, Li B, Wu YL, Xie QP: Acute pancreatitis associated left-sided portal hypertension with severe gastrointestinal bleeding treated by transcatheter splenic artery embolization: a case report and literature review. J Zheijang Univ Sci B 2013;14:549-554.

14 Petermann A, Chabrot P, Cassagnes L, et al: Hypersplenism due to portal hypertension: retrospective evaluation of 17 patients treated by splenic embolization. Diagn Interv Imaging 2012;93:30-36.

$\checkmark 15$ Gaba RC, Katz JR, Parvinian A, et al: Splenic artery embolization: a single center experience on the safety, efficacy, and clinical outcomes. Diagn Interv Radiol 2013;19:49-55.

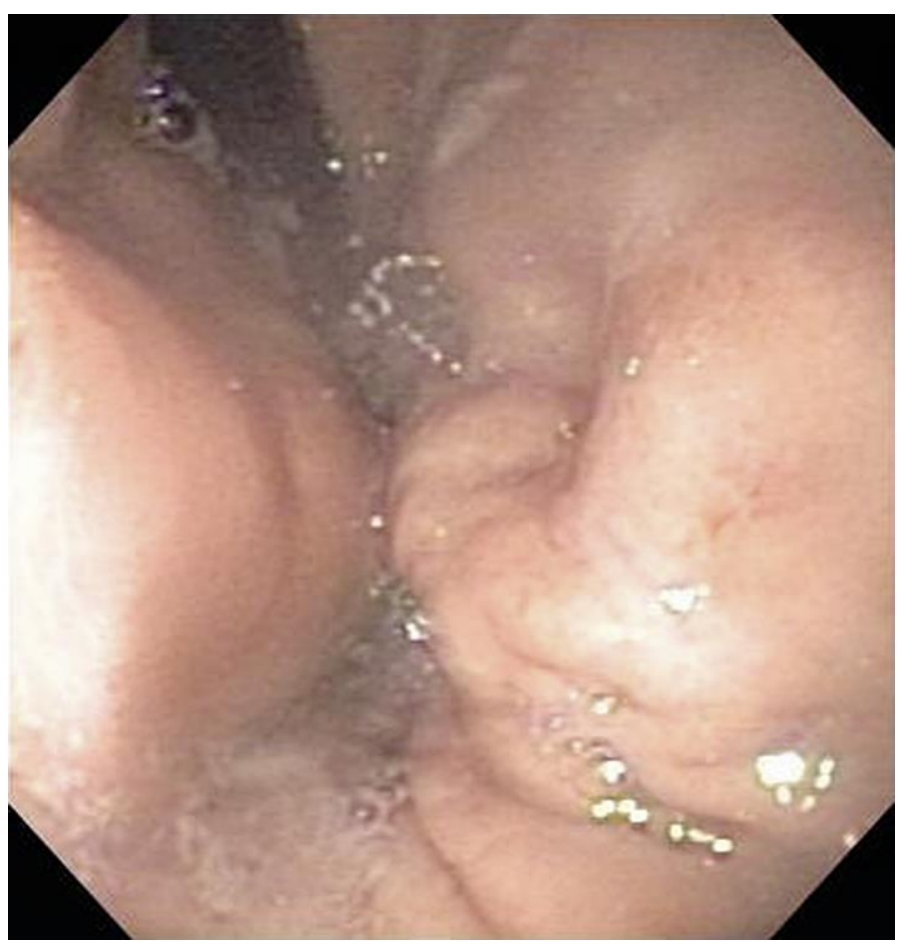

Fig. 1. EGD showing IGV $48 \mathrm{~h}$ after endoscopic therapy. 


\begin{tabular}{|c|c|c|}
\hline \multirow{2}{*}{$\begin{array}{r}\text { Case Reports in } \\
\text { Gastroenterology }\end{array}$} & \multicolumn{2}{|c|}{ Case Rep Gastroenterol 2016;10:518-524 } \\
\hline & DOI: $10.1159 / 000445184$ & $\begin{array}{l}\text { (O) } 2016 \text { The Author(s). Published by S. Karger AG, Basel } \\
\text { www.karger.com/crg }\end{array}$ \\
\hline
\end{tabular}

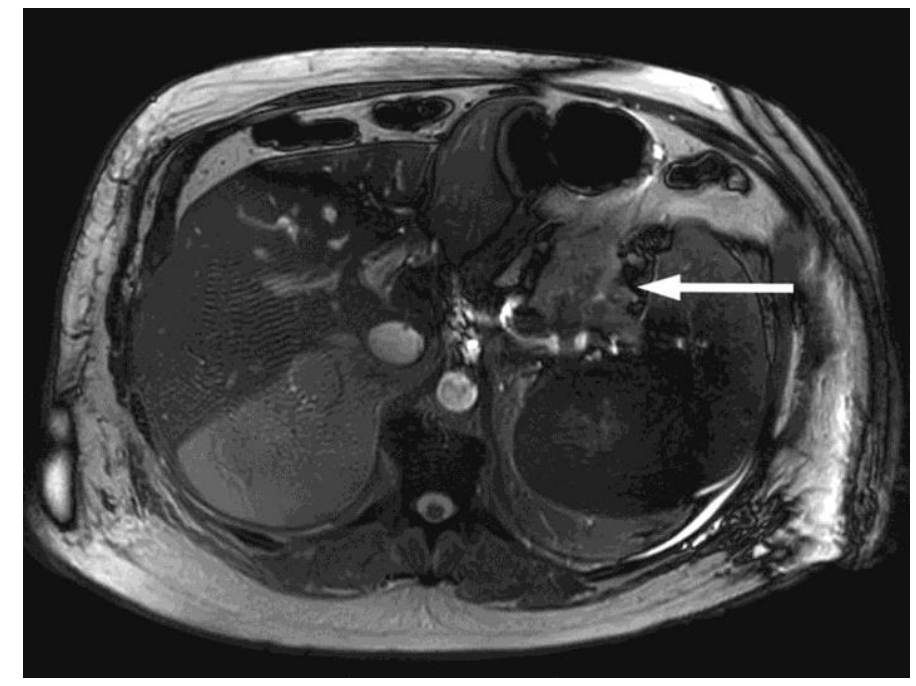

Fig. 2. MRI showing a mass in the pancreatic tail (arrow) with direct invasion into the spleen and associated splenic vein thrombosis.

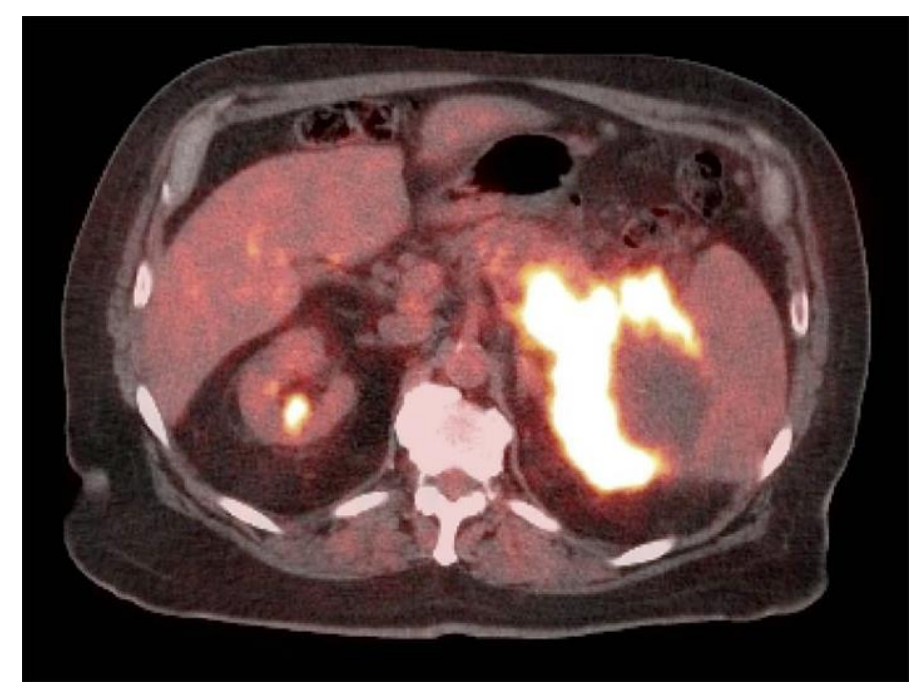

Fig. 3. Pathology slide with hematoxylin and eosin stain, consistent with diffuse large B-cell lymphoma. 